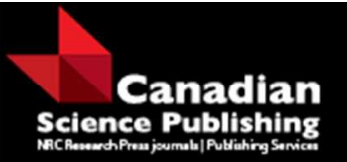

Canadian Journal of Forest Research Revue canadienne de recherche forestière

\title{
Do white spruce epicuticular wax monoterpenes follow foliar patterns?
}

\begin{tabular}{|r|l|}
\hline Journal: & Canadian Journal of Forest Research \\
\hline Manuscript ID & cjfr-2016-0056.R1 \\
\hline Manuscript Type: & Article \\
\hline Date Submitted by the Author: & $31-$ Mar-2016 \\
\hline Complete List of Authors: & $\begin{array}{l}\text { Despland, Emma; Concordia University, Biology } \\
\text { Bourdier, Thomas; Concordia University, Biology } \\
\text { Dion, Emilie; Concordia University, Biology } \\
\text { Bauce, Éric; Université Laval, Département des sciences du bois et de la } \\
\text { forêt }\end{array}$ \\
\hline Keyword: & Picea glauca, leaf surface, terpenoids, natural resistance, phytochemistry \\
\hline & \multicolumn{2}{|c}{} \\
\hline
\end{tabular}

SCHOLARONE ${ }^{\text {Im }}$

Manuscripts 
Do white spruce epicuticular wax monoterpenes follow foliar patterns?

Emma Despland, Biology Department, Concordia University (Emma.Despland@Concordia.ca)

Thomas Bourdier, Biology Department, Concordia University (Thomas.Bourdier@gmail.com)

Emilie Dion, Biology Department, Concordia University (Dion.Emilie@ymail.com) Current address: Department of Biological Sciences, National University of Singapore

Eric Bauce, Sciences du Bois et de la Forêt, Faculté de Foresterie et Géomatique, Laval University (Eric.Bauce@vrex.ulaval.ca)

For correspondence:

Emma Despland

Biology Department, Concordia University

7141 Sherbrooke West

Montreal H4B 1R6

$514848-2881$

Emma.Despland@Concordia.ca 


\section{Abstract}

2 We examine the extent to which foliar monoterpenes are trapped in the epicuticular waxes, as

3 part of an investigation into their role in natural defense against folivores. We monitored

4 concentrations in white spruce (Picea glauca) previous-year foliage and expanding foliage and

5 their epicuticular waxes, over the 2010 (14 trees) and 2011 (25 trees) growing seasons. In 2010,

6 concentrations were low in spring, and increased over the summer; in 2011 they stayed low.

7 The monoterpene profile of individual trees was similar between years, and showed a consistent

8 pattern over the growing season: in expanding foliage, $\delta$-3-carene was only present in spring,

9 whereas bornyl acetate increased over the season. Individual wax monoterpene profiles

10 correlated with those of foliage, but the total concentration showed a different phenological

11 pattern. Total content remained constant throughout the growing season on previous-year

12 foliage, but decreased on expanding foliage. Electron microscopy suggests this is due to changes

13 in stomatal wax plugs and their role in blocking evaporation from the stomata. These findings

14 suggest that insects contacting the leaf surface will receive accurate information from the wax

15 chemical make-up about the monoterpene mix but not about overall monoterpene levels.

16 Key words: Picea glauca, leaf surface, terpenoids, natural resistance. 


\section{Introduction}

18 Terpenoids are key players in the defense systems of conifers and many coniferous trees

19 produce a broad diversity of terpenoid products. Variation in monoterpene content occurs

20 between environments (e.g. it increases under drought conditions), following challenges (e.g.

21 synthesis often increases after wounding or treatment with methyl jasmonate) and between

22 tissues (e.g. levels are generally higher in stems than in needles). In addition, copious amounts

23 of monoterpenes are emitted daily by conifer foliage (Kesselmeier and Staudt 1999).

24 Monoterpene tissue pools and emissions respond differently to various challenges, and this

25 plasticity in expression presumably reflects the ecological roles of these compounds

26 (Gershenzon and Dudareva 2007, Huber et al. 2004, Keeling and Bohlmann 2006). Indeed, stem

27 monoterpenes are thought to be effective in defense against bark beetles, the most important

28 killers of conifer trees ((Phillips and Croteau 1999), but see also (Keeling 2016)), and emitted

29 monoterpenes can act as attractants of herbivores and of their natural enemies (Phillips and

30 Croteau 1999, (Langenheim 1994), and possibly be involved in plant-plant communication

31 (Huber et al. 2004).

32 However, the ecological role of monoterpenes within needles is less clear (Martin et al. 2003b).

33 It has been suggested that monoterpenes are toxic to folivores (Kumbasli and Bauce 2013), but

34 performance experiments give ambiguous results (Mattson et al. 1991, Gershenzon and

35 Dudareva 2007). Both herbivory (Litvak and Monson 1998) and treatment with MeJA (Martin et

36 al. 2003b) lead to an increase in foliar monoterpene synthesis, but foliar pools remain stable

37 because of an increased emission of the newly produced compounds. Foliar monoterpene pools

38 are at a crossroads, where chemosynthetic pathways, damage-linked induction, stress response,

39 stomatal emission, resin duct storage and translocation to other tissues interact. The foliar pool 
40 of monoterpenes is a transient state, very dynamic and can change over days or even hours

41 (Martin et al. 2003). It is nonetheless ecologically relevant for organisms interacting with the 42 leaf.

43 Another pool of conifer monoterpenes that has received virtually no attention is that in the 44 epicuticular waxes on needles. Monoterpenes are synthesized during daylight and diffuse out 45 from leaf mesophyll cells in proportion to the vapor pressure inside the needle, mostly through 46 the stomata, but also through the cuticle (Lerdau et al. 1997). Foliar epicuticular waxes can

47 influence monoterpene emission (Steinbauer et al. 2004), as monoterpenes are lipid soluble and 48 can be absorbed into the waxes as they diffuse out through the stomata (Muller and Riederer 49 2005). Monoterpenes in epicuticular waxes can influence herbivore feeding or oviposition 50 (Steinbauer et al. 2004; Ennis et al. 2015), as well as the invasion by plant pathogens and the 51 growth of lichens, fungi and other epiphytic organisms (Martin et al. 2003). Patterns of foliar 52 monoterpene synthesis in response to various environmental cues have been considered in 53 terms of their effect on foliar pools, on translocation to other tissues and on emission, but not 54 on epicuticular wax content. This avenue deserves further attention given the important role of 55 epicuticular waxes in plant interactions with other organisms (Eigenbrode and Espelie 1995).

56 The white spruce (Picea glauca) genome has recently been sequenced (Birol et al. 2013). This

57 tree exhibits at least 69 unique and transcriptionally active genes for terpene synthases, 58 including at least 15 monoterpene synthases, and most of these are involved in the synthesis of 59 several different terpenoid products (Keeling et al. 2011). Synthesis has been characterised in 60 different stem tissues (Abbott et al. 2010) and monoterpenes have been detected in the needle 61 epicuticular wax (Pruegel and Lognay 1996, Bourdier 2012). In this study, we characterize 62 variation in white spruce foliar monoterpenes, from early to late in the growing season, 
63 between expanding and mature foliage, and between internal needle contents and epicuticular

64 waxes, and link this variation to wax structures on the needle surface and to functional 65 ecological roles of these compounds.

\section{Materials and Methods}

\section{Foliage collection}

68 Foliage was collected from a white spruce plantation established in 1963 near Drummondville

69 (Quebec, Canada) on four dates during spring and summer of 2010 and 2011 (May $5^{\text {th }}$ and $18^{\text {th }}$, 70 June $14^{\text {th }}$ and July $12^{\text {th }}$ in 2010 and May $7^{\text {th }}$ and $20^{\text {th }}$, June $15^{\text {th }}$ and July $12^{\text {th }}$ in 2011). These 71 dates correspond to bud flush, expanding foliage and mature foliage.

72 Thirteen trees were used in 2010 and 12 additional trees were added in 2011. Foliage samples

73 were packed on dry ice and taken to the laboratory at Laval University. Twenty needles were 74 removed from each sample, sealed in vials and preserved at $-80^{\circ} \mathrm{C}$.

\section{Chemical analysis}

76 Foliar monoterpenes were extracted by grinding 20 needles from each sample in liquid nitrogen

77 and then extracting the contents with a 2:3 methanol:hexane solution (Daoust et al. 2010).

78 Two wax samples were extracted from each foliage sample: first, to measure the amount of 79 epicuticular wax coating the needles, 200 needles were weighed and dipped in chloroform for $8010 \mathrm{~s}$. The solution was filtered and evaporated, and the residue weighed (Gordon et al 1998).

81 These data are only available for the last three sampling dates of 2010. Second, to determine 82 the monoterpenes present in the waxes, 50 needles were put into $1 \mathrm{ml}$ of hexane-tetradecane 83 (1l-120 $\mu$ l) solution for 30 seconds under Vortex agitation (Rivet and Albert 1990). 
84 Both foliar and wax extracts were analyzed as per (Daoust et al. 2010) using a Varian model

853900 gas chromatograph equipped with a flame ionization detector and a SPB-5 fused silica

86 capillary column $(30 \mathrm{~m} \times 0.25 \mathrm{~mm}$ ) (Varian, Inc., Palo Alto, California, USA). Initial needle dry

87 weight was used to estimate monoterpene concentrations.

\section{Scanning Electron Microscopy}

89 Whole needles were fixed on aluminium stubs with carbon double-sided tape and sputter-

90 coated with a thin layer of platinum using a JEOL JFC 1100 ion sputter. The samples were

91 observed in a JEOL JSM 6510 scanning electron microscope.

92 Photographs were taken from at least two sides of each quadrangular needle and from the base

93 to the tip. Five needles from 3 trees and 3 sampling dates were analyzed.

\section{Statistical analysis}

95 We used a repeated-measures ANOVA to evaluate the overall effect of foliar age (current or 96 previous year), phenology (early May, late May, June and July) and their interactions on

97 variations in total monoterpene concentration. Multivariate analysis of variance (MANOVA)

98 with the same design examined the fractional composition of different monoterpenes. Separate

99 analyses were done for the two years of the study (2010 and 2011) and for the needles and 100 waxes.

101 Spearman correlations were used to examine the relationship between monoterpene content in 102 needles and in their overlaying wax, and in needle monoterpene content between years. 103 Spearman`s rank correlations were also used to compare the order of percent composition of 104 individual monoterpenes between years, foliar ages and phenologies. 


\section{Results}

\section{Monoterpene composition}

107 There were 7 major ( $\alpha$-pinene, camphene, myrcene, $\beta$-pinene, limonene, bornyl acetate, $\delta$-3-

108 carene) and 3 minor (thujone, terpinolene, $\alpha$-phelladrene) monoterpene components (Figure 1).

109 The latter were not detected in the majority of samples and hence were excluded from analysis.

110 Needle monoterpene composition is correlated between the two years of study, but positive 111 relationships are significant for limonene, myrcene and camphene only (see Figure 2).

112 Correlations between trees in the proportion of each monoterpene show that $\beta$-pinene and 113 limonene are associated, and correlate negatively with myrcene, camphene and bornyl acetate 114 (see Table 4).

\section{Inter-annual variation}

116 The monoterpene profiles of needles showed different patterns in 2010 and 2011 (Figure 1).

117 Results for 2011 were similar whether the new trees were included or not.

118 The lower total amount of monoterpenes observed in 2011 represented lower proportions of $\beta$ -

119 pinene, myrcene and camphene, but higher relative concentrations of $\alpha$-pinene and bornyl 120 acetate. B-pinene increased over the growing season in 2010 (contributing to the rise in total 121 monoterpene content), but stayed constant (old foliage) or even decreased (new foliage) in 122 2011. By contrast, myrcene was high in expanding foliage in the spring of 2010, decreasing 123 gradually over the season, but remained consistently low in 2011 (see Figure 1 and Table 2).

124 Weather data from the Environment Canada station in Drummondville show that the summer of 1252010 was slightly warmer (mean temperature May-July , 2010: $18.8{ }^{\circ} \mathrm{C} ; 2011: 18,4{ }^{\circ} \mathrm{C}$; average 126 1913-2013: $16.9^{\circ} \mathrm{C}$ ) and considerably drier (total rain May-July, 2010: $296 \mathrm{~mm}$; 2011: $357 \mathrm{~mm}$, 
127 average 1913-2013: $295 \mathrm{~mm}$ ). In addition, the winter preceding the 2010 field season was

128 milder (mean temperature Dec. - Apr., 2010: $-0.33^{\circ} \mathrm{C}, 2011:-3.9^{\circ} \mathrm{C}$, average $1913-2013:-5.1^{\circ} \mathrm{C}$ ),

129 with less snowfall (total snow fall Dec.-Apr., 2010: $196 \mathrm{~cm}$; 2011: $224 \mathrm{~cm}$, average 1913-2013:

$130215 \mathrm{~cm})$. In 2011, there were still $10 \mathrm{~cm}$ of snow on the ground on the last day of March but

131 none at all in 2010.

\section{Seasonal patterns}

133 A repeated-measures Anova on needle total content in 2010 shows that monoterpenes increase 134 during the year $\left(F_{3,91}=15.21, p<0.0001\right)$, in a similar fashion in both current-year and previous135 year foliage (needle age not significant, Figure $1 \mathrm{a}$ and b). In 2011, monoterpene levels were 136 low during the entire growing season (date of harvest not significant), and lower in old foliage 137 than in current-year needles $\left(F_{1,174}=8.69, p=0.003\right.$; Figure $1 \mathrm{c}$ and $\left.\mathrm{d}\right)$.

138 A similar Anova on wax for 2010 shows that monoterpenes in wax on current-year needles start 139 high in May then drop in the summer (Figure 1 e), whereas levels are consistently low in the wax 140 on old foliage (Figure $1 \mathrm{f}$ ) (harvest date: $F_{3,101}=11.68, p<0.0001$; needle age: $F_{1,101}=14.01, p$ $141<0.0001$; interaction: $F_{3,101}=13.10, p<0.0001$ ). In 2011, there is no significant variation in levels 142 of wax monoterpenes, but values are very low throughout, approaching the limit of detection by 143 the instrument and hence making analysis difficult. These data are therefore not included. 144 Repeated measures Anova on the amount of epicuticular wax in 2010 shows no significant 145 effect of either foliage age or sampling date - see Table 1.

146 Multiple analysis of variance on the monoterpene composition (proportion of total represented 147 by each of the 7 major components) of needle samples shows that the composition of 148 monoterpenes varies significantly during the season, between current-year and previous year 149 foliage, and between 2010 and 2011 (see Figure 1a, b, c and d). A peak of $\delta$-3-carene occurs in 
150 the spring in expanding foliage, and then the concentration of $\delta$-3-carene decreases over the

151 season as camphene and bornyl acetate increase. These seasonal changes are not observed in

152 old foliage, where the composition of monoterpenes stays relatively constant over the growing

153 season. This pattern was observed in both years (see Figure 1 and Table 2).

154 A similar pattern is observed in epicuticular waxes in 2010: $\delta$-3-carene peaks in the spring in 155 expanding foliage, then decreases over the growing season, while remaining low throughout the 156 season in old foliage. Bornyl acetate and camphene increase over the growing season in current 157 year foliage. Myrcene decreases over the growing season in expanding foliage, but remains 158 consistently low in old foliage (see Table 3).

\section{Wax structure and monoterpene content}

160 Correlations between tree averages show significant positive relationships between the 161 proportion of each monoterpene in a tree's needles and its epicuticular waxes (Figure 2).

162 Figure 3 shows images from two trees at the three later sampling dates in 2010: a broad band of 163 stomata (4-7 rows) is seen on each side of the midrib. The tubular wax structure is visible 164 between the stomatal rows, as are the crystalline wax plugs in the epistomatal chambers. The 165 plug is eroded in the July foliage (Figure 3: C, F \& I).

\section{Discussion}

\section{Variation in monoterpene profiles}

168 The results show different patterns in the two years of study: foliar monoterpenes increased 169 over the growing season in the warm dry year (2010) but stayed low in the cooler, wetter year 170 (2011). In both years, the monoterpene composition of expanding foliage changed over the 
171 season, showing a spring peak in $\delta$-3-carene, followed by a gradual increase in bornyl acetate

172 over the summer. Individual trees showed a strong correlation in the blend of monoterpenes,

173 between years and between foliage and wax, as expected since this blend is largely under

174 genetic control (Huber et al. 2004). However, the concentration of monoterpenes in epicuticular

175 wax decreased over the growing season, despite the fact that the amount of wax covering the

176 needles remained constant, possibly due to lesser coverage of stomatal wax plugs.

177 The low monoterpene concentrations in 2011 (in needles and waxes) are presumably linked to 178 the wet conditions. Indeed, drought and mild heat stress are linked to increased monoterpene 179 pools (Kainulainen et al. 1992) and emissions (Niinemets 2010) in several conifers. In spruce, it is 180 mostly the non-oxygenated compounds ( $\beta$-pinene, myrcene and camphene, as observed in our 181 study) that increase with drought (Kainulainen et al. 1992). In 2010, a warmer, drier year, foliar 182 monoterpenes increased over the growing season. This seasonal increase has previously been 183 observed in white spruce (Von Rudloff 1972) and other conifers (Litvak and Monson 1998), 184 despite the fact that storage organs for monoterpenes are produced early in leaf ontogeny and 185 rapidly filled (Lerdau et al. 1994). The levels we measured in needles are within the range 186 measured in white spruce foliage (Mattson et al. 1991; Fuentealba and Bauce 2012).

187 Two compounds merit particular note for showing seasonal patterns consistent with the 188 literature: $\delta$-3-carene was only observed in the spring (as in another conifer species (Thoss et al. 189 2007)), whereas bornyl acetate increased gradually as the needles develop (as previously 190 observed in white spruce (Von Rudloff 1972)).

\section{Epicuticular waxes and monoterpene dynamics}

192 We show that the monoterpene blend in epicuticular wax is similar to that in the needle, but 193 decreases over the growing season while foliar contents increase. 
194 The epidermal surface of spruce needles is covered with a layer of wax tubes, made up mostly of 195 nonacosan-10-ol that forms tubular aggregates, mixed with a variety of non-volatile organic 196 compounds including carboxyl acids, alcohols, alkanes and phenolics (Gordon et al. 1998). These 197 tubes are most dense between the rows of stomata, and the stomata themselves are blocked 198 with a plug of crystalline wax structures (Figure 3; (Percy and Baker 1990)). This wax develops 199 very early during leaf expansion: first, it fills the epistomatal chamber prior to budbreak, then 200 becomes visible on the epidermis. Within a week, needles already show a pattern of wax 201 deposition similar to fully grown needles (Percy and Baker 1990).

202 Cross-section through stomata shows that the plug consists of intermeshed wax tubes and 203 extends from just above the epidermal surface down to the upper surfaces of the guard cells, a 204 depth of 15-18 $\mu \mathrm{m}$ (Jeffree et al. 1971). This plug reduces stomatal area for diffusion; modelling 205 suggests that the presence of wax in young needles can reduces transpiration by $2 / 3$ (Jeffree et 206 al. 1971). It seems likely that this wax also impedes diffusion of larger molecules such as 207 monoterpenes.

208 We show that the amount of wax covering needles remains the same over the growing season, 209 as seen in other spruces (Gordon et al. 1998), and as expected, since wax is formed very early in 210 needle development (Percy and Baker 1990). However, our electron micrographs suggest some 211 erosion of these stomatal plugs during the summer. Despite the fact that the relative 212 concentration of wax on the needles does not change as the needles elongate, the stomata are 213 more blocked on younger foliage. This might explain why monoterpene concentrations in waxes 214 are higher on newly formed expanding foliage.

215 Limiting water loss is most important in young foliage (Jeffree et al. 1971) and it is possible that 216 the wax plugs are most effective in occluding stomates early in the growing season. 


\section{Functional role of foliar monoterpenes}

218 The effects of monoterpenes on folivores have been difficult to characterize (Mattson et al.

219 1991, Gershenzon and Dudareva 2007), due in part to the fact that monoterpenes occur in

220 blends where it is not necessarily possible to disentangle the roles of individual compounds

221 (Langenheim 1994).

222 One compound, whose effect on White spruce early spring feeders would warrant further

223 attention, is $\delta$-3-carene. We showed a $\delta$-3-carene peak in the spring with concentration

224 decreasing over the growing season. This compound is similarly expressed only during leaf

225 expansion in Scots pine (Thoss et al. 2007) and defines two chemotypes of this species.

226 Moreover, high and low levels of $\delta$-3-carene in growing shoots define Sitka spruce genotypes

227 resistant and susceptible to white pine weevil (Hall et al. 2011, Roach et al. 2014).

228 The epicuticular wax is the first point of contact of a folivore with a leaf, and therefore

229 influences decisions about feeding and oviposition (Muller and Riederer 2005). For instance,

230 female spruce budworm moths oviposit on previous year foliage in July and will therefore

231 contact only low monoterpene content in needle waxes. These are not likely to be good

232 predictors of the monoterpene concentrations that their offspring will be exposed to in

233 expanding foliage in the following year, especially considering the considerable inter-annual

234 variability in foliar monoterpene concentrations. Indeed, in our study, correlations between

235 previous-year foliage wax in July 2010 and current-year needles in May 2011 show no significant

236 values for any of the monoterpenes (data not shown). Previous work shows that ovipositing

237 female budworm moths are attracted to monoterpene emissions (Grant et al. 2007) and use

238 wax monoterpenes as a cue for host identification (Ennis et al. 2015). Similarly, ovipositing

239 sawflies use wax monoterpenes to determine between different pine species that offer varying 
240 quality foliage to offspring (Kazlauskas et al. 2011). However, our results suggest that, within

241 White spruce, wax monoterpenes are not likely to provide a good cue to laying females for 242 determining host quality for their offspring.

243 We still don't fully understand how monoterpenes affect the various selection pressures plants

244 face, but they seem to contribute to alleviating several stresses. It appears that both constitutive 245 and induced monoterpenes are important in defense against several xylophages (Huber et al. 246 2004, Keeling and Bohlmann 2006, Keeling 2016). Several monoterpenes, notably $\delta$-3-carene 247 and bornyl acetate, have been suggested to be toxic to the spruce budworm at high 248 concentrations (Kumbasli and Bauce 2013, Fuentealba and Bauce 2012). Monoterpenes are also 249 known to be active against fungi and gram-negative bacteria (Novak et al. 2014), and could 250 protect against pathogens both at the leaf surface and within leaf airspaces (Martin et al. 2003).

251 Monoterpenes might also have an internal physiological role, e.g. increasing thermal tolerance 252 of photosynthesis, decreasing evapotranspiration or limiting UV damage (Holopainen and 253 Gershenzon 2010).

254 Increasingly, molecular studies are unravelling the biochemical and genomic architecture 255 underlying monoterpene production in conifers (e.g. (Keeling et al. 2011, Hall et al. 2013, Roach 256 et al. 2014, Bohlmann et al. 2015)). However, establishing ecological roles of monoterpenes is 257 hard (Gershenzon and Dudareva 2007, Keeling 2016). Our results demonstrate a hitherto 258 ignored pool of conifer monoterpenes: that in the epicuticular waxes. We also show 259 considerable seasonal and interannual variation in monoterpenes, both in foliar pools and in 260 epicuticular waxes. Wax monoterpenes deserve further attention for their effects on organisms 261 interacting with the foliage, for their potential role as cues to these organisms, for their impact 

on monoterpene emissions and for their potential role as an endpoint for monoterpene

263 production.

\section{Acknowledgements}

265 Thanks to Paule Huron with help with field work, to Martin Charest for chemical analyses, to

266 Chris Daignault for wax measurements, to Darragh Ennis for discussions and to two anonymous

267 reviewers for helpful suggestions and comments. This work was funded by a Canadian Natural

268 Science and Engineering Research Council Collaborative Research and Development Grant to the

269 iFOR consortium.

\section{References}

271 Bohlmann, J., Gesell, A., Blaukopf, M., Madilao, L., Macaire, M.S., Withers, S., 272 Mattson, J., and Russel, J.H. 2015. The gymnosperm cytochrome P450 CYP750B1

273 catalyzes stereospecific monoterpene hydroxylation of $(+)$-sabinene in thujone

274 biosynthesis in Thuja plicata. Plant Physiology

275 Bourdier, T. 2012. Behavioral adaptations of the Eastern spruce budworm (Lepidoptera:

276 Tortricidae) to natural White spruce (Picea glauca (Moench)) resistance. M.Sc.:

277 Concordia University

278 Daoust, S., Mader, B., Bauce, E., Dussutour, A., Despland, E., and Albert, P.J. 2010.

279 Influence of epicuticular wax composition on the feeding pattern of a phytophagous

280 insect: implications for host resistance. Canadian Entomologist 142: 261-270.

281 Ennis, D., Despland, E., Chen, F., Forgione, P., and Bauce, E. 2015. Spruce budworm

282 feeding and oviposition are stimulated by monoterpenes in white spruce epicuticular wax.

283 Insect Science

284 Fuentealba, A., and Bauce, E. 2012.

285 Carryover effect of host nutritional quality on performance of spruce budworm progeny.

286 Bulletin of Entomological Research 102: 275-284.

287 Gershenzon, J., and Dudareva, N. 2007. The function of terpene natural products in the 288 natural world. Nature Chemical Biology 3: 408-414. 
Gordon, D., Percy, K., and Riding, R. 1998. Effects of u.v.-B radiation on epicuticular wax production and chemical composition of four Picea species. New Phytologist 138: 441-449.

Grant, G.G., Guo, J., MacDonald, L., and Coppens, M.D. 2007. Oviposition response of spruce budworm (Lepidoptera: Tortricidae) to host terpenes and green-leaf volatiles. Canadian Entomologist 139: 564-575.

Hall, D.E., Robert, J.A., Keeling, C.I., Domanski, D., Quesada, A.L., Jancsik, S., Kuzyk, M.A., Hamberger, B., Borchers, C.H., and Bohlmann, J. 2011. An integrated genomic, proteomic and biochemical analysis of (+)-3-carene biosynthesis in Sitka spruce (Picea sitchensis) genotypes that are resistant or susceptible to white pine weevil. Plant Journal 65: 939-948.

Hall, D.E., Yuen, M.M.S., Jancsik, S.J., Quesada, A.L., Dullat, H.K., Li, M., Henderson, H., Arango-Velez, A., Liao, N.Y., Docking, R.T., Chan, S.K., Cooke, J.E.K., Breuil, C., Jones, S.J.M., Keeling, C.I., and Bohlmann, J. 2013. Transcriptome resources and functional characterization of monoterpene synthases for two host species of the mountain pine beetle, lodgepole pine (Pinus contorta) and jack pine (Pinus banksiana). BMC Plant Biology 13: 80.

Holopainen, J.K., and Gershenzon, J. 2010. Multiple stress factors and the emission of plant VOCs. Trends in Plant Science 15: 176-184.

Huber, D.P.W., Ralph, S., and Bohlmann, J. 2004. Genomic hardwiring and phenotypic plasticity of terpenoid based defenses in conifers. Journal of Chemical Ecology 30: 23992418.

Jeffree, C.E., Johnson, P.G., and Jarvis, P.G. 1971. Epicuticular wax in the stomatal antechamber of Sitka spruce and its effects on the diffusion of water vapour and carbon dioxide. Planta 98: 1-10.

Kainulainen, P., Oksanen, J., Palomäki, V., Holopainen, J.K., and Holopainen, T. 1992. Effect of drought and waterlogging stress on needle monoterpenes of Picea abies. Canadian Journal of Botany 70: 1613.

Keeling, C.I. 2016. Bark beetle research in the postgenomic era. Advances in Insect Physiology

Keeling, C.I., Weisshaar, S., Ralph, S.G., Jancsik, S., Hamberger, B., Dullat, H.K., and Bohlmann, J. 2011. Transcriptome mining, functional characterization, and phylogeny of a large terpene synthase gene family in spruce (Picea spp.). BMC Plant Biology 11: 43.

Keeling, C.I., and Bohlmann, J. 2006. Genes, enzymes and chemicals of terpenoid diversity in the constitutive and induced defence of conifers against insects and pathogens. New Phytologist 170: 657-675. 
Kesselmeier, J., and Staudt, M. 1999. Biogenic Volatile Organic Compounds (VOC): An Overview on Emission, Physiology and Ecology. Journal of Atmospheric Chemistry 33: 23-88.

Kumbasli, M., and Bauce, E. 2013. Spruce budworm biological and nutritional performance responses to varying levels of monoterpenes. iForest 6: 310-314.

Langenheim, J. 1994. Higher plant terpenoids: a phytocentric view of their ecological role. Journal of Chemical Ecology 20: 1223-1280.

Lerdau, M., Litvak, M., and Monson, R. 1994. Plant chemical defense: monoterpenes and the growth-differentiation balance hypothesis. Trends in Ecology \& Evolution 9: 58.

Lerdau, M., Litvak, M., Palmer, P., and Monson, R. 1997. Controls over monoterpene emissions from boreal forest conifers. Tree Physiology 17: 563-569.

Litvak, M.A., and Monson, R.K. 1998. Patterns of induced and constitutive monoterpene production in conifer needles in relation to insect herbivory. Oecologia 114: 531-540.

Martin, D.M., Gershenzon, J., and Bohlmann, J. 2003. Induction of Volatile Terpene Biosynthesis and Diurnal Emission by Methyl Jasmonate in Foliage of Norway Spruce. Plant Physiology 132: 1586.

Mattson, W.J., Haack, R.A., Lawrence, R.K., and Slocum, S.S. 1991. Considering the nutritional ecology of the spruce budworm and its management. Forest Ecology and Management 39: 183-210

Muller, C., and Riederer, M. 2005. Plant surface properties in chemical ecology. Journal of Chemical Ecology 31: 2621-2651.

Niinemets, U. 2010. Mild versus severe stress and BVOCs: thresholds, priming and consequences. Trends in Plant Science 15: 145-153.

Novak, M., Krajnc, A.U., Lah, L., Zupanec, N., Kraševec, N., Križman, M., Bohlmann, J., and Komel, R. 2014. Low-density Ceratocystis polonica inoculation of Norway spruce (Picea abies) triggers accumulation of monoterpenes with antifungal properties. European Journal of Forest Research 133: 573-583.

Percy, K.E., and Baker, E.A. 1990. Effects of simulated acid rain on epicuticuar wax production, morphology, chemical composition and on cuticular membrane thickness in two clones of Sitka spruce (Picea sitchensis (Bong.) Carr.). New Phytologist 116: 79-87.

Phillips, M.A., and Croteau, R.B. 1999. Resin-based defenses in conifers. Trends in Plant Science 4: 184-190. 
357 Pruegel, B., and Lognay, G. 1996. Composition of the cuticular waxes of Picea abies and 358 P. sitchensis. Phytochemical Analysis 7: 29-36.

359 Rivet, M.P., and Albert, P.J. 1990. Oviposition behavior in spruce budworm

360 Choristoneura fumiferana (Clem.) (Lepidoptera: Tortricidae). Journal of Insect Behavior 361 3: $395-400$.

362 Roach, C.R., Hall, D.E., Zerbe, P., and Bohlmann, J. 2014. Plasticity and evolution of $363(+)$-3-carene synthase and (-)-sabinene synthase functions of a sitka spruce monoterpene 364 synthase gene family associated with weevil resistance. Journal of Biological Chemistry 365 289: 23859-23869.

366 Staudt, M., Bertin, N., Frenzel, B., and Seufert, G. 2000. Seasonal Variation in Amount 367 and Composition ofMonoterpenes Emitted by Young Pinus pinea Trees- Implications for 368 Emission Modeling. Journal of Atmospheric Chemistry 35: 77-99.

369 Steinbauer, M.J., Schiestl, F.P., and Davies, N.W. 2004. Monoterpenes and epicuticular 370 waxes help female autumn gum moth differentiate between waxy and glossy Eucalyptus 371 leaves of different ages. Journal of Chemical Ecology 30: 1117-1142.

372 Thoss, V., O'Reilly-Wapstra, J., and Iason, G.R. 2007. Assessment and Implications of 373 Intraspecific and Phenological Variability in Monoterpenes of Scots Pine ( Pinus 374 sylvestris ) Foliage. Journal of Chemical Ecology 33: 477-491.

375 Von Rudloff, E. 1972. Seasonal variation in the composition of the volatile oil of the 376 leaves, buds, and twigs of white spruce (Picea glauca). Can. J. Bot., 50:1595-1603 


\section{Tables}

Table 1 : Amount of epicuticular wax (mg/g dry mass) present on foliage in 2010.

\begin{tabular}{lll}
\hline Foliage year & Date & Wax $(\mathrm{mg} / \mathrm{g})$ \\
\hline current & 18 May 2010 & $11.86+/-3.62$ \\
current & 14 June 2010 & $10.53+/-1.79$ \\
current & 12 July 2010 & $10.37+/-2.68$ \\
previous & 18 May 2010 & $10.81+/-3.15$ \\
previous & 14 June 2010 & $11.14+/-2.39$ \\
& & $11.51+/-2.98$ \\
previous & 12 July 2010 & \\
\hline
\end{tabular}


Table 2: Output of a Manova on proportion of each monoterpene in needles, showing p-values for all effects tested. Predictors included in the model include main effects of year (Y, 2010 vs 2011, d.f. = 1), foliar age (A, current vs previous year, d.f. $=1$ ) and date of harvest ( $D$, early may, late mate, june or july, treated as a regression, d.f. $=1$ ) as well as the interactions between them. Residual $d . f=241 .=241$. Effects significant at the $p=0.01$ level are highlighted.

\begin{tabular}{|c|c|c|c|c|c|c|c|c|}
\hline & apinene & $\beta$ pinene & Limonene & Myrcene & Camphene & Bornyl & Carene & total \\
\hline Date & 0.018 & 0.337 & 0.501 & 0.120 & $<0.0001$ & $<0.0001$ & $<0.0001$ & $<0.0001$ \\
\hline Year & $<0.0001$ & $<0.0001$ & 0.158 & 0.002 & 0.003 & 0.001 & 0.547 & $<0.0001$ \\
\hline Age & 0.011 & 0.004 & 0.996 & 0.334 & $<0.0001$ & $<0.0001$ & $<0.0001$ & $<0.0001$ \\
\hline$D * Y$ & 0.28 & 0.004 & 0.008 & 0.014 & 0.582 & 0.205 & 0.263 & 0.007 \\
\hline$D * A$ & 0.013 & $<0.0001$ & 0.977 & 0.115 & $<0.0001$ & $<0.0001$ & $<0.0001$ & $<0.0001$ \\
\hline$Y * A$ & 0.294 & 0.9 & 0.103 & 0.32 & 0.907 & 0.008 & 0.628 & 0.15 \\
\hline$D^{*} Y^{*} A$ & 0.363 & 0.001 & 0.002 & 0.021 & 0.479 & 0.753 & 0.684 & 0.005 \\
\hline
\end{tabular}


Table 3 : Output of a Manova on the proportion of each monoterpene in wax in 2010. Predictors included in the model include main effects of foliar age ( $A$, current vs previous year, d.f. $=1)$ and date of harvest ( $D$, early may, late mate, june or july, treated as a regression, d.f. $=1$ ) as well as the interactions between them. Residual d.f $=241$. Effects significant at the $p=0.01$ level are highlighted.

\begin{tabular}{lllllllll}
\hline & apinene & $\beta$ pinene & Limonene & Myrcene & Camphene & Bornyl & Carene & total \\
& & & & & & & \\
\hline Date & 0.997 & 0.319 & 0.0690 & 0.0002 & 0.0003 & 0.023 & 0.009 & $<0.0001$ \\
& & & & & & & & \\
Age & 0.347 & 0.035 & 0.5377 & 0.019 & 0.671 & 0.854 & 0.156 & $<0.0001$ \\
& & & & & & & & \\
D*A & 0.109 & 0.356 & 0.1892 & 0.0002 & 0.016 & 0.049 & 0.006 & $<0.0001$ \\
& & & & & & & & \\
\hline
\end{tabular}


Table 4: Pearson correlations between proportions of different monoterpenes in needles in 2010. Current-year and previous-year foliage pooled. Values significant at the $p=0.05$ level $(|r|>0.5)$ in bold.

\begin{tabular}{|c|c|c|c|c|c|c|c|}
\hline & $\alpha$-pinene & $\beta$-pinene & Limonene & Myrcene & Camphene & Bornyl & Carene \\
\hline$\alpha$-pinene & 1 & -0.56 & -0.72 & 0.15 & 0.38 & 0.03 & 0.42 \\
\hline$\beta$-pinene & & 1 & 0.70 & -0.61 & -0.85 & -0.55 & -0.28 \\
\hline Limonene & & & 1 & -0.14 & -0.52 & -0.34 & -0.32 \\
\hline Myrcene & & & & 1 & 0.46 & 0.32 & -0.18 \\
\hline Camphene & & & & & 1 & 0.63 & 0.22 \\
\hline Bornyl & & & & & & 1 & 0.20 \\
\hline Carene & & & & & & & 1 \\
\hline
\end{tabular}




\section{List of figures}

Figure 1 : Monoterpene concentrations measured on four sampling dates in 2010 (14 trees) and 2011 (25 trees), ppm per mass of foliage assayed in current and previous-year needles (a-b: 2010; c-d: 2011) and in epicuticular waxes coating those needles (e-f: 2010).

Figure 2: Correlations in proportion of monoterpene content represented by each compound: a) between needles and waxes in 2010 ( $\alpha$-pinene $r=0.66, p=0.01$; $\beta$-pinene $r=0.89, p<0.001$; limonene $r=0.72, p=0.003$; myrcene $r=.066, p=0.01$; camphene $r=0.48, p=0.08$; bornyl acetate $r=0.58, p=0.03$; carene $r=0.90, p<0.001 ; N=14$ trees), b) between needles in 2010 and 2011 ( $\alpha$-pinene $r=0.45, p=0.12 ; \beta$-pinene $r=-0.19, p=0.52$; limonene $r=0.76, p=$ 0.002 ; myrcene $r=0.74, p=0.003$; camphene $r=0.55, p=0.05$; bornyl acetate $r=0.46, p=0.12$; carene $r=0.47, p=0.10$; $\mathrm{N}=13$ trees). Current-year and previous-year foliage pooled for both analyses.

Figure 3: Scanning electron micrographs of needles from two individual trees (panels A-F, tree A10; G-I: tree A2) on 3 sampling dates (panels A, D, G: 18 May 2010; B, E, H: 14 June 2010; C, F, I: 12 July 2010). Panels A-C show rows of stomata on either side of the leaf midrib. The density of wax on the leaf surface is greater in the zone between stomata than outside. Plugs of crystalline wax tubes are visible in epistomatal chambers; they appear more eroded as the season progresses, but maintain their crystalline structure. 


\section{Page 23 of 25}

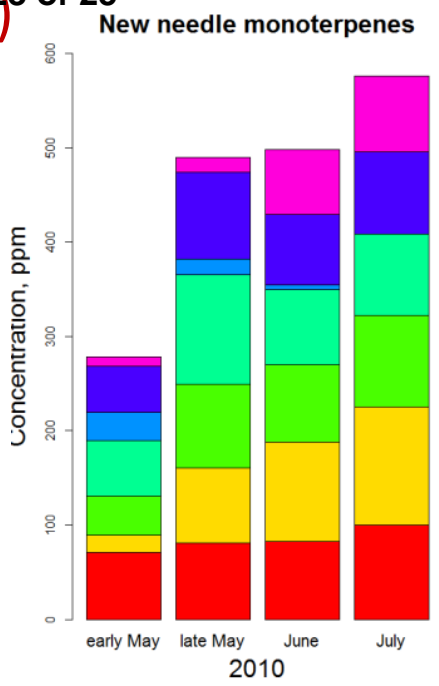

(c)

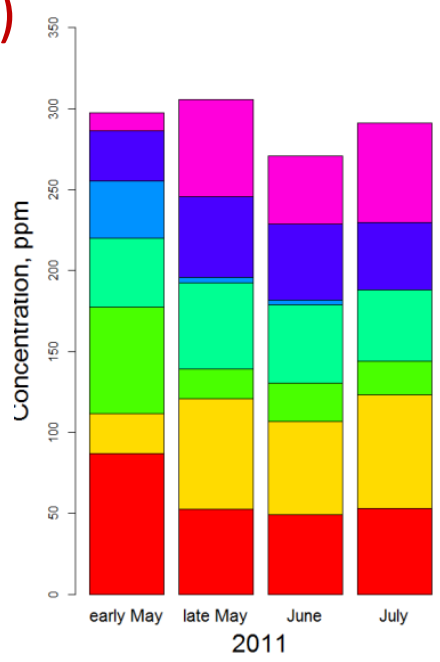

(e)

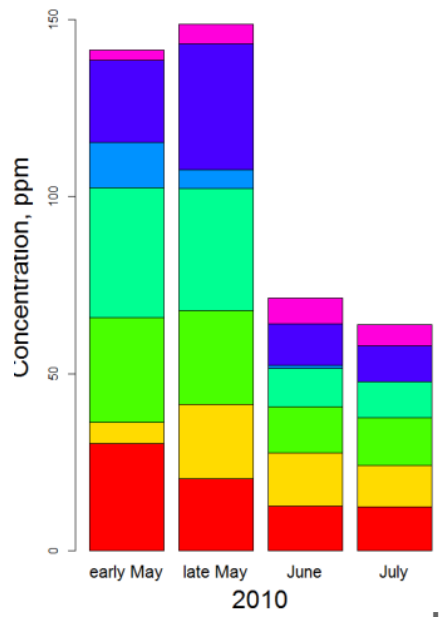

\section{Canaqian Journal of Forest Research}

Old needle monoterpenes

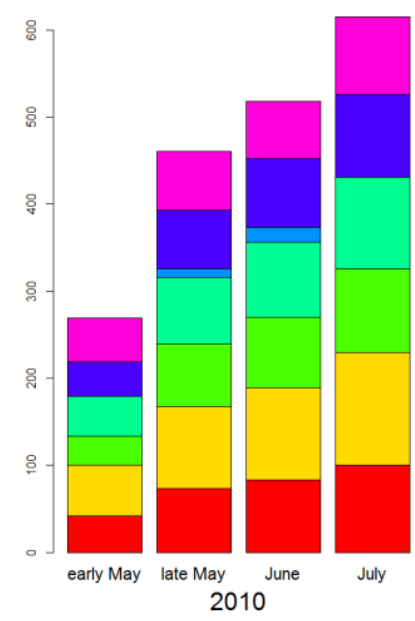

(d)

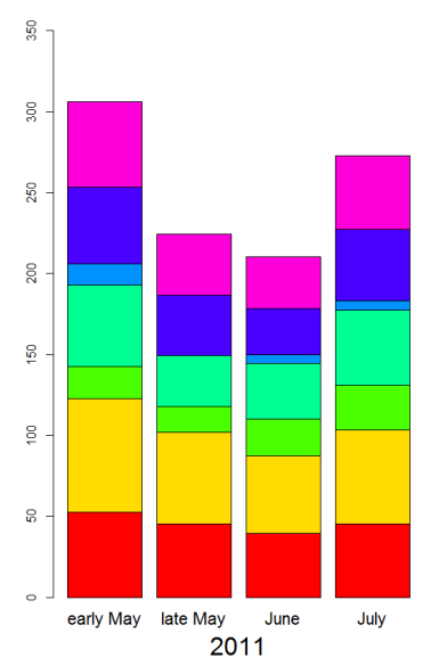

(f)

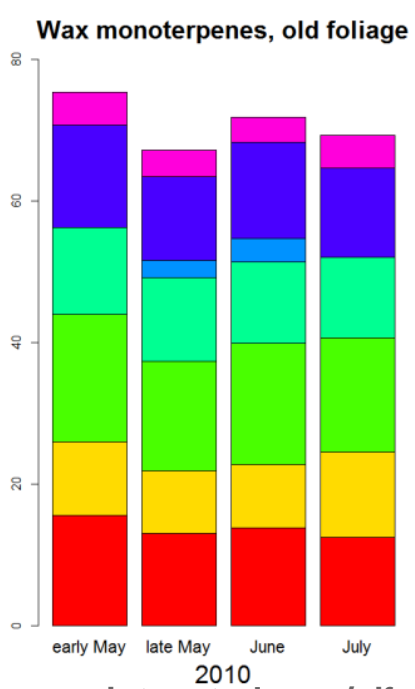

https://mc06.manuscriptcentral.com/cjfr-pubs 

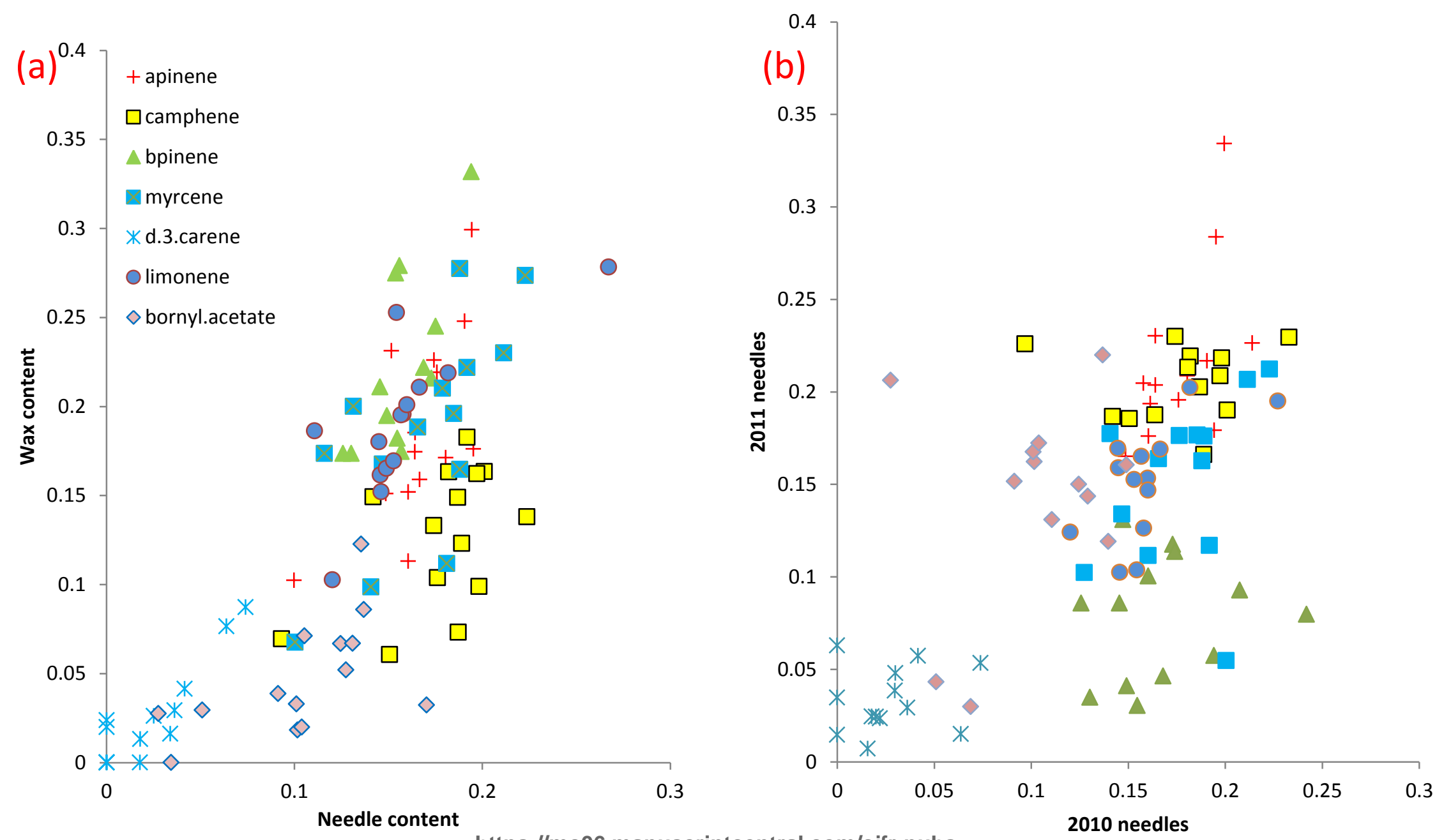

https://mc06.manuscriptcentral.com/cjfr-pubs 
Page 25 of 2518 May
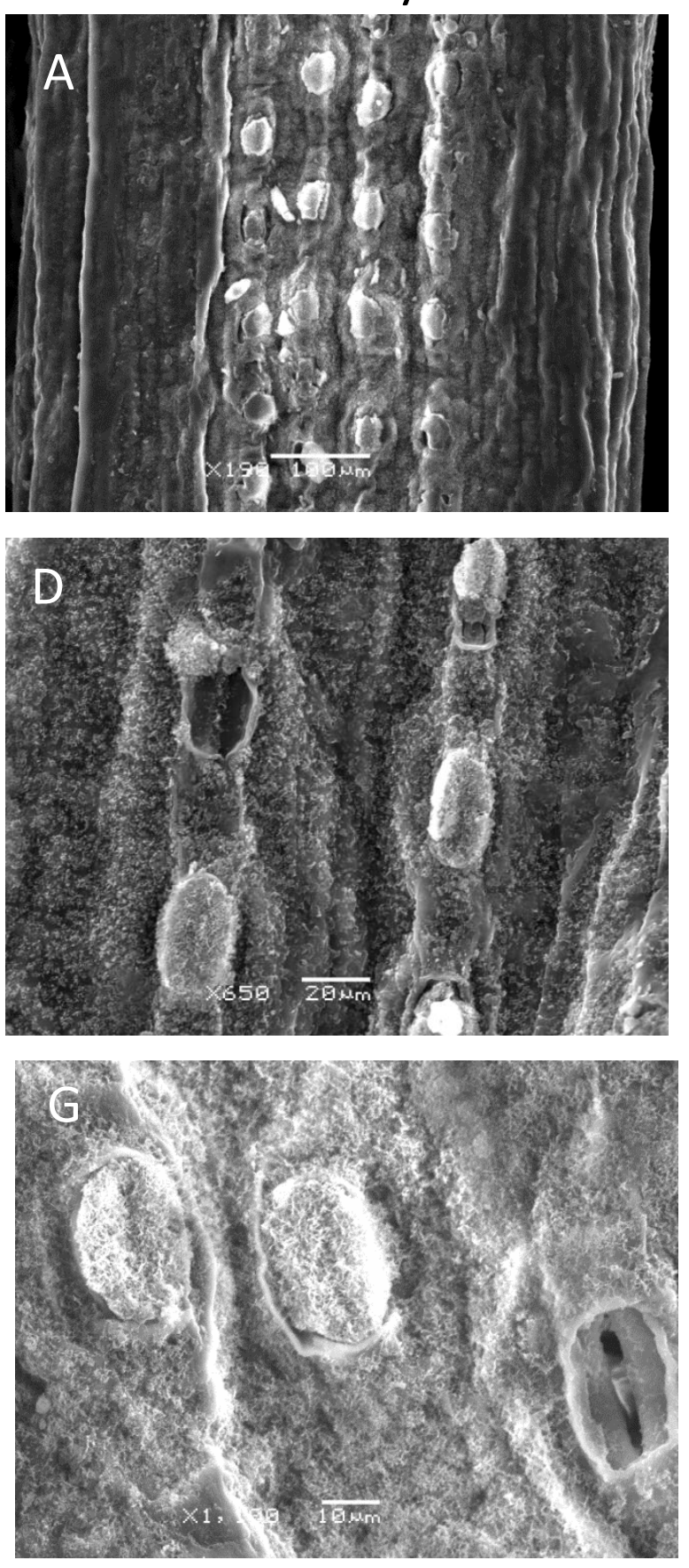

Canadian Joџrnaj effifgrest Research
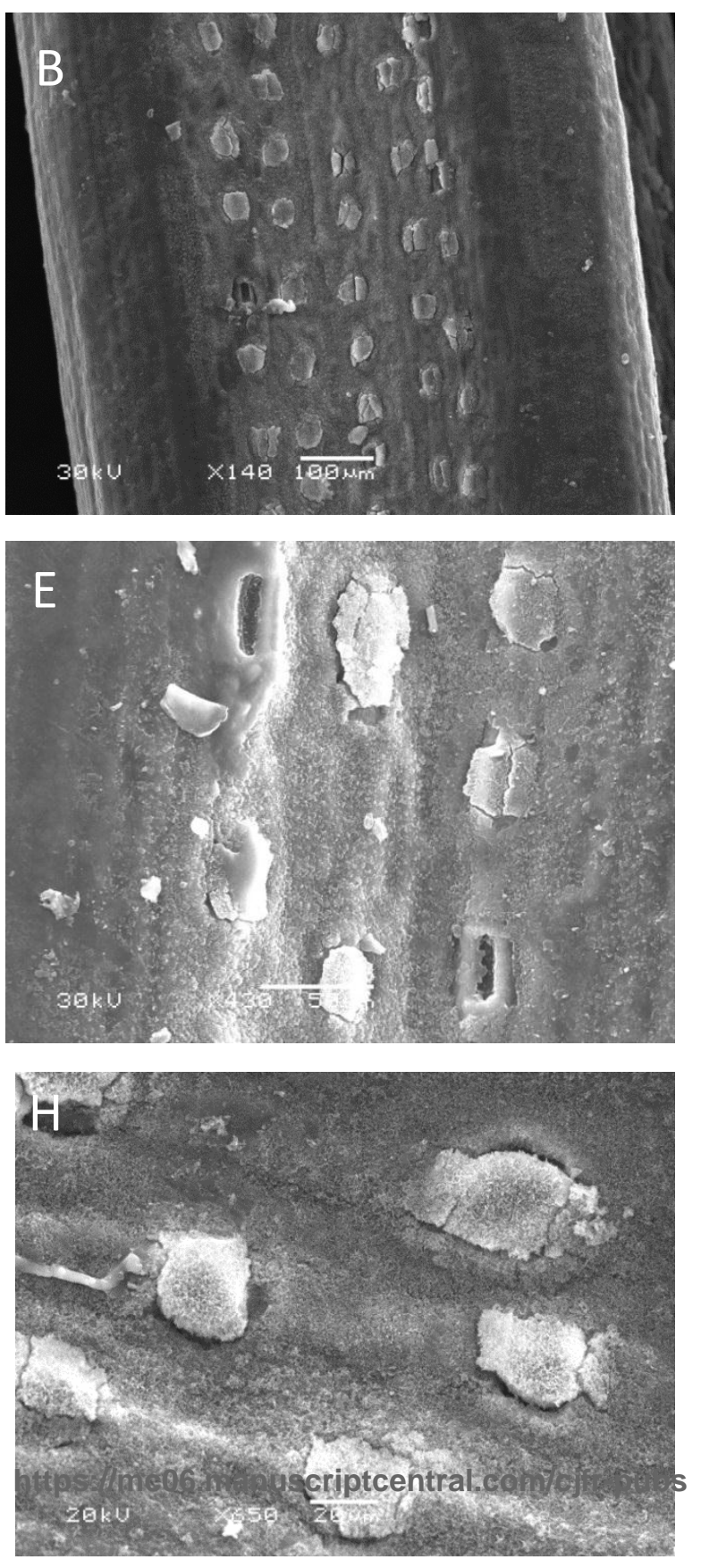

12 July
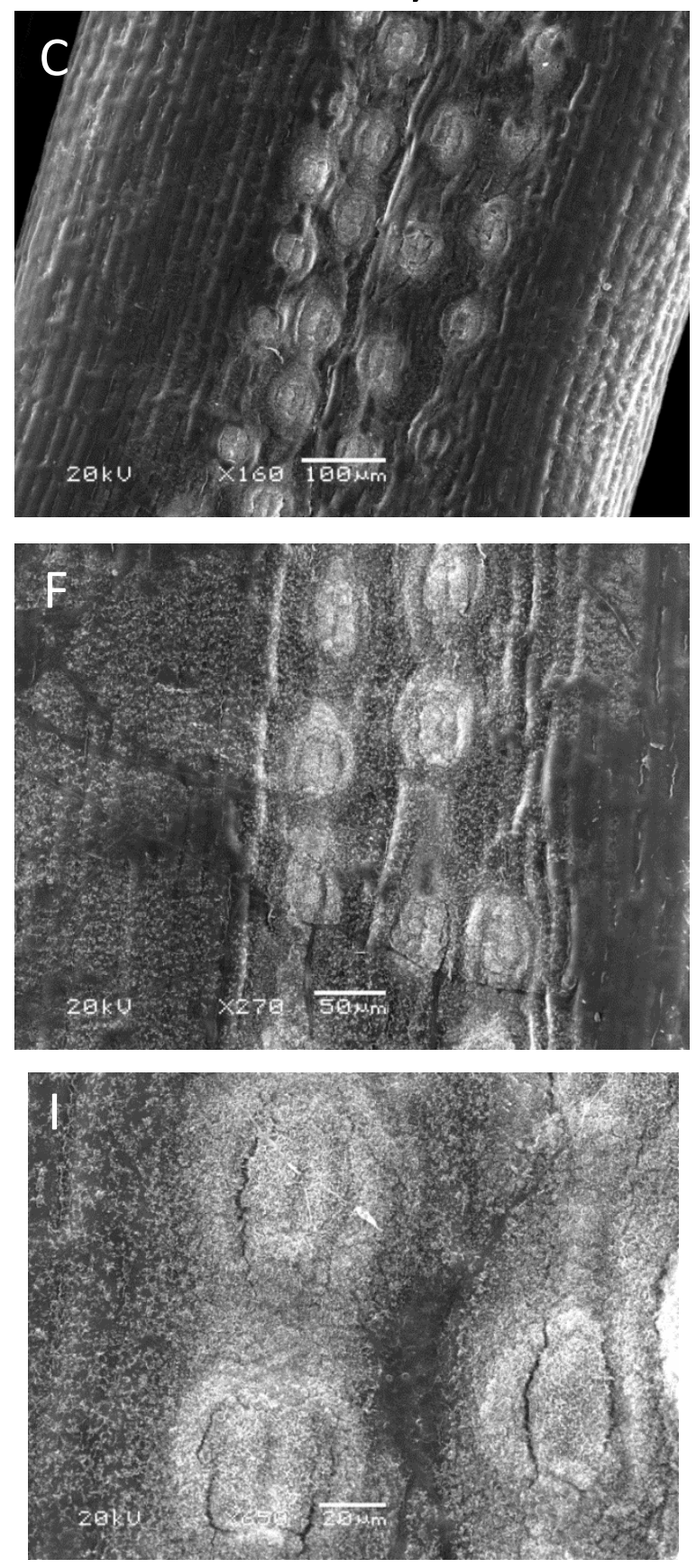